ISSN: 0213-2060

DOI: http://dx.doi.org/10.14201/shhme201432215238

\title{
LOS MUNICIPIOS CONTRA EL CENTRALISMO MONÁRQUICO. LA OPOSICIÓN CONCEJIL A LOS ALCALDES MAYORES DE LAS PROFESIONES SANITARIAS EN LA CASTILLA DEL SIGLO XV ${ }^{1}$
}

\section{Municipalities against Monarchical Centralism. The Municipal Opposition to the Royal Judges of the Health Professions in $15^{\text {th }}$ Century Castile}

José Damián GONZÁLEZ ARCE

Depto. de Economía Aplicada. Facultad de Economía y Empresa. Universidad de Murcia. Campus de Espinardo.E-30100 MURCIA. C. e.: josedam@um.es

Recibido: 2013-04-13

Revisado: 2013-07-09

Aceptado: 2013-09-200

BIBLID [0213-2060(2014)32;215-238]

RESUMEN: Durante el siglo xv los monarcas castellanos intentaron situar bajo su control a las profesiones sanitarias mediante el nombramiento de alcaldes mayores de los médicos, cirujanos, sacamuelas, veterinarios y otros. El cometido de estos funcionarios reales era el de examinar, y en ocasiones juzgar, el trabajo de dichos profesionales y conceder licencias para ejercer a quienes encontrasen idóneos. Para ello tuvieron que arrebatar estas competencias a los municipios, que se resistieron a perderlas. Tanto esta resistencia, como la corrupción en la que cayeron los alcaldes mayores y sus delegados, así como las rivalidades habidas entre ellos, impidieron que se formasen auténticos órganos colegiados para el gobierno de la sanidad humana y animal del reino. Esta era al menos la intención de los Reyes Católicos, que, no obstante, pusieron las bases legislativas para que comenzasen a funcionar tales tribunales, tanto el del Real Protomedicato como el del Real Protoalbeiterato.

Palabras clave: Protomédicos. Protoalbéitares. Exámenes. Corrupción. Poder municipal.

1 Este artículo ha sido realizado en el marco del proyecto HAR2011-26218, titulado «Fiscalidad y sociedad en la Corona de Castilla al sur del Tajo», cuyo investigador principal es Ángel Galán Sánchez, catedrático de la Universidad de Málaga. 
ABSTRACT: During the fifteenth Century Castilian, the monarchs tried to bring under its control to the health professions, through the appointment of judges over physicians, surgeons, tooth-puller, veterinarians and others. The role of these royal officials was to examine, and sometimes judge, the work of these professionals and grant licenses to those who qualified. It also provides a listing of those officials and their activities. To serve as judges had to take these powers to municipalities, who refused to lose. This resistance, the corruption in which fell the judges and their deputies and clashes among themselves, not allowed they appeared authentic collegiate systems for the government of Castilla-health. This was at least the intention of the Catholic Monarchs. They at least put the legislative basis for they began to run such courts, the Protomedicato and Protoalbeiterato.

Keywords: Protomédicos. Protoalbéitares. Examinations. Corruption. Municipal power.

SUMARIO: 0 Introducción. $1 \mathrm{La}$ supervisión de las profesiones sanitarias. 2. La paulatina pérdida de competencias concejiles. 2.1 Murcia. 2.2 Sevilla. 2.3 Otros municipios. 3 El caso de la sanidad aninal. 4 Conclusión.

\section{INTRODUCCIÓN}

El poder político medieval estuvo atomizado entre varias instituciones y grupos sociales, de los que el rey era su cabeza visible. Los monarcas debieron contar con una nobleza terrateniente y un alto clero que, frecuentemente, eran más poderosos que ellos mismos. Esta situación no resultó tan extrema en Castilla, debido al protagonismo monárquico en la lucha contra el Islam, aunque sus reyes hubieron de emprender un largo proceso para construir un Estado centralizado. Iniciado en el siglo XIII, con Fernando III, que potenció la cancillería y burocracia regias, continuado luego por su hijo, Alfonso X, quien reintrodujo el derecho romano, Alfonso XI y su heredero Pedro I prosiguieron en el XIV estas reformas jurídico-administrativas y combatieron el poder de la aristocracia. Algo similar ocurrió con Juan II, ya en el siglo XV, quien, con la ayuda de su valido, el condestable Álvaro de Luna, puso las bases para una monarquía nacional, en lucha contra la nobleza banderiza, encabezada por los infantes de Aragón, primero, y luego por su propio hijo, el futuro Enrique IV.

Los Reyes Católicos culminaron este proceso al final de la centuria, tras imponerse a sus contrarios en la guerra civil que les condujo al solio. Sus profundas reformas, así como la unión dinástica de las coronas de Castilla y Aragón, condujeron a una de las primeras monarquías nacionales, precedente del Estado autoritario más poderoso del siglo Xvi. Para ello, los soberanos redujeron el poder de la nobleza y clero, que desde entonces solamente pudieron ejercerlo como delegados regios, e hicieron patente su autoridad en los municipios, mejor acatada en los de realengo y de forma más difusa en los seńoríos. Estas reformas abarcaron otros ámbitos, más allá de la política, tanto económicos y sociales, como religiosos y culturales.

El interés por el fomento de la producción les hizo legislar sobre actividades consideradas importantes para el desarrollo o el bien común. Emitieron ordenanzas generales para la 
JOSÉ DAMIÁN GONZÁLEZ ARCE

LOS MUNICIPIOS CONTRA EL CENTRALISMO MONÁRQUICO. LA OPOSICIÓN CONCEJIL

A LOS ALCALDES MAYORES DE LAS PROFESIONES SANITARIAS EN LA CASTILLA DEL SIGLO XV

industria textil, la peletera o la cerera ${ }^{2}$. También reglamentaron las profesiones de abogados, procuradores y notarios, si bien no llegaron a regular las sanitarias ${ }^{3}$. No obstante, a pesar de carecer de ordenamientos reales, este sector fundamental para el interés general fue sometido a unos supervisores especiales, a veces conocidos como alcaldes y otras como examinadores, encargados de evaluar a los profesionales de la salud.

El objetivo del presente estudio es analizar la función de estos agentes estatales, nombrados por los monarcas para controlar a los sanadores que trabajaban en el reino. Delegados regios que, para poder cumplir su cometido, hubieron de salvar la oposición concejil y señorial, contrarias a este proceso centralizador.

Para ello, en el siguiente apartado repasaré cómo aparecieron los dedicados a la salud humana y cómo adquirieron competencias. Posteriormente, veremos que estas resultaron difíciles de ejercer, debido a la resistencia municipal, pues los ayuntamientos no cedieron fácilmente sus atribuciones, tras varios siglos de jurisdicción casi exclusiva en la materia. Podremos así diferenciar los consistorios según su éxito para evitar la actuación de los supervisores y sus lugartenientes, que resultó más fácil en las ciudades importantes, donde antes se dejó notar la autoridad real, y más tardía y parcial en las poblaciones y territorios periféricos, en los señoríos o en el ámbito rural. Como ejemplo de lo anterior se presentan los casos de Sevilla y Murcia. La poca fortuna inicial del sistema, no implementado totalmente hasta el siglo XVI, se explica, asimismo, por la catadura de los delegados regios, en ocasiones más atentos a su interés personal que al servicio público. De manera que, aparte de enfrentarse entre ellos, y no llegar a constituir un verdadero órgano colegiado con atribuciones jurídicas y judiciales, como pretendieron los Reyes Católicos, cometieron abusos. Tales como nombrar subdelegados territoriales a cambio de dinero. Venalidad que los abocó a la corrupción, pues dichos lugartenientes o no estaban suficientemente capacitados o se dejaban cohechar a su vez por los profesionales, para recuperar su inversión en las lugartenencias y lucrarse con su desempeño. El resultado fue que dejaban trabajar a personas inhábiles e incapaces a cambio de sobornos. Por último, en un apartado diferente, me ocuparé del caso de la sanidad animal, paralelo al de la humana, pero con peculiaridades propias.

Este trabajo ha requerido del manejo de abundante documentación hasta ahora no empleada, procedente de más de una decena de archivos locales y nacionales, aquellos en los que se ha conservado información de detalle para este tema de investigación y sobre este período, lo que constituye un análisis comparativo de la sanidad castellana medieval y del avance y extensión del poder central de la monarquía prácticamente inédito.

\section{LA SUPERVISIÓN DE LAS PROFESIONES SANITARIAS}

Uno de los primeros textos donde aparece la exigencia de exámenes para ejercer una profesión es el Fuero Real, redactado por los juristas de Alfonso X en la segunda mitad del

2 GonzÁlez Arce, José Damián. «La organización de la producción textil y las corporaciones gremiales en las ordenanzas generales de paños castellanas (1494-1511)». Anuario de Estudios Medievales, 2008, vol. 38, n. ${ }^{\text {2 }}$, pp. 707-759.

3 González Arce, José Damián. «Los proyectos de ordenanzas generales de médicos, cirujanos y boticarios de Castilla (ca. 1491-1513)». Dynamis, 2011, vol. 31, n. ${ }^{1}$, pp. 207-226. 
siglo XIII. En él se deja a los concejos la evaluación de los médicos y cirujanos, que, una vez hallados capaces, obtenían «licentia practicandi» en su término municipal en forma de carta de examen. Con el tiempo, estas atribuciones fueron asumidas progresivamente por los alcaldes mayores, no sin resistencia de las ciudades. Algunos autores sitúan hacia 1345 su aparición, cuando Alfonso XI dio a ciertos agentes regios poderes especiales para perseguir prácticas ilegales. Sus sucesores continuaron con esta política. Por esas fechas aparecerían también las cartas de examen reales, antes de que las Cortes de 1371 establecieran que la cancillería otorgase venias para poder examinar a otros a aquellos médicos que acudiesen a la corte. De modo que, previa a la aparición de los alcaldes mayores como tales, ciertos galenos reales procedieron al examen de algunos físicos; o, más bien, asesoraron a la cancillería regia en la expedición de licencias. Caso de lo ocurrido en 1385, cuando el de Juan I, el bachiller en física Juan Guillén, firmó una carta de examen recibida en Murcia, en favor del sevillano Yuzaf Abenalazar, al que encontró perteneciente para usar el oficio en todas partes.

Resulta bastante bien conocida la trayectoria vital y profesional de la mayoría de los alcaldes y examinadores mayores del siglo xv. Aquí bastará con una relación (Tabla 1), para en el apartado siguiente analizar cómo se produjo su paulatina asunción de competencias, primero teórica y luego de hecho, en detrimento de los municipios, que se resistieron a la pérdida del control de la salud local en favor de estos agentes reales, distantes y a menudo demasiado motivados por el afán de lucro, que los llevó a la descoordinación, el enfrentamiento personal, la venalidad y la corrupción, lo que no hizo sino aumentar la desconfianza y oposición ${ }^{4}$.

4 Amasuno Sárraga, Marcelino. Medicina ante la ley. La licencia practicandi y el ejercicio de la medicina en la Castilla bajomedieval. Salamanca: Junta de Castilla y León, 2002, pp. 33-35, 45-47, 53-56, pássim; Parrilla Hermida, Miguel. Apuntes históricos del Protomedicato; antecedentes y organismos herederos. Madrid: Anales de la Real Academia Nacional de Medicina, 1977; Campos Díez, María Soledad. El Real tribunal del Protomedicato castellano (siglos XIV-XIX). Cuenca: Ediciones de la Universidad de Castilla-La Mancha, 1999; García BAllester, Luis. La búsqueda de la salud: sanadores y enfermos en la España medieval. Barcelona: Ediciones Península, 2001. Para una actualización sobre la polémica en torno a la aparición del protomedicato castellano, SÁnchez Álvarez, Julio. El Protomedicato navarro y las cofradías sanitarias de San Cosme y San Damián. El control social de las profesiones sanitarias en Navarra (1496-1829). Pamplona: Gobierno de Navarra, 2010, pp. 49-54. Otros trabajos sobre esta cuestión, Alonso Cortés, Narciso. "Dos médicos de los Reyes Católicos». Hispania, 1951, vol. 46, pp. 606-657; Barrio OgaYar, Jesús. Organización del Protomedicato en España, tesis doctoral, Universidad de Granada, 1978; CAmpos Díez, María Soledad. «El Protomedicato en la administración central de la Monarquía Hispánica». Dynamis, 1996, vol. 16, pp. 43-58; Folch Jou, Guillermo. "La figura del protomédico, como examinador, anterior a la disposición de los Reyes Católicos de 1477». Boletín de la Sociedad Española de Historia de la Farmacia, 1976, vol. 27, n.o 108; Gómez Mampaso, María Valentina. "Los alcaldes examinadores mayores. Origen y competencia». Boletín de la Real Academia de la Historia, 1983, vol. 180, n. ${ }^{3}$ 3, pp. 551-562; Iвоrra, Pascual. Historia del Protomedicato en España (1477-1822). Valladolid: Universidad de Valladolid, 1987; López Terrada, María Luz. «Los estudios historicomédicos sobre el Tribunal del Protomedicato y las profesiones y ocupaciones sanitarias en la Monarquía Hispánica durante los siglos XVI al XviıI». Dynamis, 1996, vol. 16, pp. 21-42; Muñoz Garrido, Rafael y Muñiz Fernández, Carmen. Fuentes legales de la medicina española (siglos XIII-XIX). Salamanca: Universidad de Salamanca, 1969; Roldán GUERRERO, Rafael. «Los orígenes del Tribunal del Real Protomedicato de Castilla». Asclepio, 1960, vol. 12, pp. 249-254; Valverde López, José Luis. Origen del Tribunal del Protomedicato. Granada, 1972; Valverde López, José Luis. «Controversias jurisdiccionales del Protomedicato castellano». Asclepio, 1978, vol. 30-31, pp. 403-424. 
JOSÉ DAMIÁN GONZÁLEZ ARCE

LOS MUNICIPIOS CONTRA EL CENTRALISMO MONÁRQUICO. LA OPOSICIÓN CONCEJIL

A LOS ALCALDES MAYORES DE LAS PROFESIONES SANITARIAS EN LA CASTILLA DEL SIGLO XV

TABLA 1.- Relación de alcaldes mayores y sus competencias.

\begin{tabular}{|c|c|c|c|c|}
\hline Ańo & Reinado & Alcaldes mayores & Especialidad & Competencias \\
\hline S. XIV & Alfonso XI & Maestre Esteban & Cirugía & \multirow[t]{3}{*}{ [1] Asesor cancillería regia. } \\
\hline 1385 & Juan I & Juan Guillén & \multirow[t]{2}{*}{ Medicina } & \\
\hline & $\begin{array}{l}\text { Enrique III- } \\
\text { Juan II }\end{array}$ & Alfonso Chirino & & \\
\hline \multirow[t]{3}{*}{1420} & \multirow[t]{8}{*}{ Juan II } & $\begin{array}{l}\text { Diego Rodríguez de Santa } \\
\text { Cruz }\end{array}$ & \multirow[t]{2}{*}{$\begin{array}{l}\text { Medicina, cirugía y } \\
\text { farmacia }\end{array}$} & \multirow{3}{*}{$\begin{array}{l}\text { [2] Examen a profesionales, delegados } \\
\text { territoriales, sanción a incapaces y de- } \\
\text { sobedientes, cobro tasas examen. }\end{array}$} \\
\hline & & Martín González de Lucena & & \\
\hline & & Maestre Pedro de Ávila & \multirow[t]{2}{*}{ Cirugía } & \\
\hline \multirow[t]{2}{*}{1438} & & Martín de Cabañas & & \\
\hline & & Juan de Toledo & \multirow[t]{2}{*}{ Medicina y farmacia } & \\
\hline 1439 & & Gómez García de Salamanca & & $\begin{array}{l}\text { [3] Apartado 2, y visitador de lazaretos, } \\
\text { exámenes universales, porteros emplaza- } \\
\text { dores, multas de } 3.000 \text { mrs. y tasas de } \\
5 \text { doblas. }\end{array}$ \\
\hline $1447 ?$ & & Andrés Rodríguez & Cirugía & \\
\hline \multirow[t]{2}{*}{1450} & & Juan Álvarez de Calatayud & Medicina y farmacia & (Delegado de García de Salamanca). \\
\hline & $\begin{array}{l}\text { (Príncipe } \\
\text { Enrique) }\end{array}$ & $\begin{array}{l}\text { Juan Muńoz } \\
\text { y Martín Gutiérrez Bonifaz }\end{array}$ & Flebotomía & $\begin{array}{l}\text { [4] Examen de profesionales, delegados } \\
\text { territoriales, emplazamientos, confirma- } \\
\text { ción cartas examen ( } 12 \text { mrs.), tasas exa- } \\
\text { men ( } 2 \text { doblas) y vigilancia del trabajo } \\
\text { en festivos. }\end{array}$ \\
\hline & \multirow[t]{2}{*}{ Juan II } & Alfonso de Roa & Cirugía & \\
\hline $1452 ?$ & & Lope Gutiérrez de Melgar & Flebotomía & \\
\hline $1455 ?$ & \multirow[t]{2}{*}{ Enrique IV } & Juan Fernández de Soria & Medicina y farmacia & \\
\hline \multirow[t]{4}{*}{1455} & & $\begin{array}{l}\text { Juan Muńoz } \\
\text { y Martín Gutiérrez Bonifaz }\end{array}$ & Flebotomía & Confirmación. \\
\hline & \begin{tabular}{|l} 
Príncipe \\
Alfonso)
\end{tabular} & Juan Rodríguez de Toledo & \multirow[t]{2}{*}{ Medicina y farmacia } & \\
\hline & \multirow[t]{2}{*}{ Enrique IV } & Nicolás Polonio & & \\
\hline & & \multirow[t]{2}{*}{ Juan de Guadalupe } & \multirow{4}{*}{$\begin{array}{l}\text { Medicina, cirugía y } \\
\text { farmacia }\end{array}$} & \\
\hline 1474 & \multirow{14}{*}{$\begin{array}{l}\text { Reyes } \\
\text { Católicos }\end{array}$} & & & \multirow{2}{*}{$\begin{array}{l}\text { [5] Apartado 3, confirmación, capacidad } \\
\text { de reexaminar, exámenes de médicos y } \\
\text { cirujanos: } 5 \text { doblas, restantes: } 3 \text {. }\end{array}$} \\
\hline \multirow[t]{3}{*}{1475} & & $\begin{array}{l}\text { Juan Tején } \\
\text { y Juan Rodríguez de Toledo }\end{array}$ & & \\
\hline & & Abraham Xarafi & & Médicos y cirujanos mudéjares. \\
\hline & & Rodrigo del Lunar & Flebotomía & Apartado 4. \\
\hline \multirow[t]{2}{*}{1477} & & y Pascual Palacios & & Confirmación. \\
\hline & & $\begin{array}{l}\text { Juan de Guadalupe, Juan } \\
\text { Tején, Juan Rodríguez de } \\
\text { Toledo y Lorenzo Badoz }\end{array}$ & \multirow[t]{2}{*}{$\begin{array}{l}\text { Medicina, cirugía y } \\
\text { farmacia }\end{array}$} & $\begin{array}{l}{[6] \text { Apartado 5, confirmación, com- }} \\
\text { parecencia de todos los profesionales, } \\
\text { potestad judicial, examen personal y no } \\
\text { delegado. }\end{array}$ \\
\hline 1479 & & $\begin{array}{l}\text { Juan de Guadalupe } \\
\text { y Juan de Ribasaltas }\end{array}$ & & Confirmación. \\
\hline 1486 & & $\begin{array}{l}\text { Rodrigo del Lunar } \\
\text { y Pascual Palacios }\end{array}$ & Flebotomía & Confirmación. \\
\hline 1491 & & Nicolás de Soto & Medicina, cirugía y & Apartado 6. \\
\hline 1494 & & Gabriel Álvarez Abarca & farmacia & [7] Apartado 6 y revocación delegaciones. \\
\hline & & Francisco Palacios & Flebotomía & Apartado 4. \\
\hline 1497 & & $\begin{array}{l}\text { Fernando Álvarez de la Reina } \\
\text { y Juan de la Parra }\end{array}$ & $\begin{array}{l}\text { Medicina, cirugía y } \\
\text { farmacia }\end{array}$ & Apartado 7. \\
\hline 1498 & & $\begin{array}{l}\text { Nicolás de Soto, Juan de } \\
\text { Guadalupe y Julián Gutiérrez }\end{array}$ & & Apartado 7 y confirmación. \\
\hline 1500 & & $\begin{array}{l}\text { Rodrigo del Lunar } \\
\text { y Francisco Palacios }\end{array}$ & Flebotomía & Revocación delegados territoriales. \\
\hline
\end{tabular}


A los datos de la Tabla 1 hay que hacer aclaraciones sobre alcaldes desconocidos o poco tratados. En primer lugar, el doctor Martín González de Lucena, médico real que ejerció como alcalde mayor junto con Diego Rodríguez de Santa Cruz, por lo que habría sido designado como tal en una fecha próxima a la que lo fue este, pero del que apenas contamos con una noticia aislada del año 1434, como veremos más abajo. Hacia 1447 el alcalde de los cirujanos era Andrés Rodríguez, sustituido, tras su óbito, por el maestro Alfonso de Roa; mientras que alrededor de 1452, el de los barberos era Lope Gutiérrez de Melgar; y, hacia 1455, el de los médicos, Juan Fernández de Soria. Que Enrique IV nombrase alcaldes y examinadores mayores de barberos, o alfajemes, sangradores, o flebotomianos, y sacamuelas, cuando era todavía príncipe (1450), a sus propios barberos, los segovianos Juan Muñoz, al tiempo repostero de camas, y Martín Gutiérrez Bonifaz, se explica por el enfrentamiento contra su padre Juan II, en plena guerra civil. Después los ratificó, en 1455 , tras ser coronado rey5.

En enero de 1475 los Reyes Católicos designaron alcalde y examinador mayor a Rodrigo del Lunar, también segoviano. Este no podía ir contra los intereses de Gutiérrez de Melgar. En abril era confirmado en el cargo y junto a él situado Pascual Palacios, para que actuasen colegiada o individualmente, como los médicos. Ambos eran ratificados en 1477, con idénticas competencias que los alcaldes de Enrique IV, pues se reproduce casi al pie de la letra la credencial de 1450. Caso, entre otras, de la supervisión de los fraudes y errores, de manera que los profesionales estaban obligados a acudir a sus emplazamientos; pero, a diferencia de los protomédicos, no gozaban de jurisdicción civil ni criminal, ni de capacidad de juzgar. También fueron revocadas las alcaldías de Juan II y Enrique IV ${ }^{6}$. En 1486, los soberanos volvían a confirmar a Lunar y Palacios, en este caso Francisco, en lugar de Pascual, a la vez que actualizaron sus cometidos ${ }^{7}$. En 1500 los monarcas, debido a los abusos y corrupción, acordaron revocar las lugartenencias dadas por ambos, a los que prohibieron volver a concederlas, que en adelante debían examinar personalmente, conjuntamente o por separado ${ }^{8}$.

Desde este reinado, los alcaldes y examinadores mayores lo fueron de todas las actividades sanitarias, excepto los antedichos flebotomianos, es decir, de médicos, o físicos,

5 Archivo Municipal de Jerez de la Frontera (AMJF), Acta Capitular (AC), 1438, fols. 45r-47v. Archivo Municipal de Murcia (AMM), Cartulario Real (CR) 1453-1478, fols. 85r-86v. Molina Grande, María del Carmen. Documentos de Enrique IV. Murcia: Real Academia Alfonso X El Sabio, 1988, pp. 64-68.

6 Campos Díez, El Real tribunal, pp. 37-39. Ese ańo 1477, Lunar, junto con el alcalde del cabildo y cofradía de barberos de Segovia, Miguel de Useda, presentaron un testimonio ante un escribano en el que recogían parte de las ordenanzas del gremio local (Archivo General de Simancas (AGS), Registro General del Sello (RGS), 1477-05, 18). En 1485 era recibida en Jerez de la Frontera la carta de nombramiento de 1477 (AMJF, AC 1485, fols. 126r-v, 136r-v).

7 Fernández Gómez, Marcos; Ostos Salcedo, Pilar, y Pardo Rodríguez, María Luisa. El tumbo de los Reyes Católicos del concejo de Sevilla. Madrid: Centro de Estudios Ramón Areces, 1998, vol. 7, pp. 327-332; Pérez Escolano, Víctor y Villanueva Sandino, Fernando (eds.). Ordenanzas de Sevilla. Sevilla: Oficina Técnica de Arquitectura e Ingeniería, 1975, fols. 238v-240r. Muy probablemente Pascual y Francisco fuesen hermanos, y el segundo sustituyese al primero tras su muerte; lo cierto es que Francisco fue nombrado alcalde mayor en 1494 (AGS, RGS, 1494-04, 93), por lo que en los documentos de 1486, que son copias posteriores, bien pudo ser reemplazado el nombre de Pascual por el de Francisco.

8 Libro de las bulas y pragmáticas de los Reyes Católicos. Madrid: Instituto de Espańa, 1973, ed. facs., vol. I, fols. 156r-158r. Nueva Recopilación, III, XVIII. 
JOSÉ DAMIÁN GONZÁLEZ ARCE

LOS MUNICIPIOS CONTRA EL CENTRALISMO MONÁRQUICO. LA OPOSICIÓN CONCEJIL

A LOS ALCALDES MAYORES DE LAS PROFESIONES SANITARIAS EN LA CASTILLA DEL SIGLO XV

cirujanos, ensalmadores, o componedores de huesos, boticarios, especieros, herbolarios y de los cuidadores de los leprosos, o responsables de los lazaretos, tanto hombres como mujeres, cristianos, judíos o musulmanes ${ }^{9}$. En diciembre de 1474 los soberanos ratificaron al licenciado Juan de Guadalupe, designado por Enrique IV. En abril de 1475 pusieron junto al anterior a Juan Tején. En julio lo hacían con el doctor Juan Rodríguez de Toledo, catedrático en Valladolid y alcalde mayor del usurpador príncipe Alfonso (hermano de Enrique IV e Isabel I), que era nieto del primero instituido por Juan II, Diego Rodríguez de Santa Cruz. En enero de 1475 nombraron al doctor Abraham Xarafi, médico del arzobispo de Toledo, como alcalde mayor de los físicos y cirujanos mudéjares, no de los boticarios, pues les estaba prohibido ejercer de tales desde Juan $\mathrm{II}^{10}$. De Fernández de Guadalupe se pensaba que finó en 1498, pero veremos más abajo que estaba vivo todavía en 1501. Luego pertenecieron al protomedicato otros galenos reales. En 1497, Fernando Álvarez de la Reina (o doctor de la Reina), en sustitución de su hermano, Gabriel Álvarez Abarca (o Gabriel Álvarez de la Reina), y Juan de la Parra; por lo que tuvo 5 miembros, los antedichos más Soto, Gutiérrez y Guadalupe.

La prueba de que los alcaldes mayores no llegaron a actuar de forma coordinada como un tribunal colegiado la encontramos en 1495. Ese año Juan de Palacio, vecino de Laredo, examinado y aprobado como médico y cirujano por Ribasaltas, para mayor demostración de su valía profesional fue a la corte a reexaminarse con Soto. Sin embargo, mientras tanto, a raíz de una falsa denuncia, fue llamado por Rodríguez de Toledo a Valladolid, para que confirmase su maestría. Como no pudo acudir, por estar haciendo el reexamen, fue prendado con la mitad de sus bienes, al tiempo que Rodríguez le prohibía ejercer hasta que lo examinase personalmente. Palacio recusó a Rodríguez por ser amigo de su denunciante, mientras dicho alcalde adujo que el denunciado lo había rechazado por descubrir que no era hábil y vendía medicinas falsas, y así poder examinarse con Soto y de la Reina. Los reyes pusieron el caso en manos del Consejo Real. No obstante, el denunciante volvió a insistir ante los protomédicos en 1496, y en esta ocasión obtuvo una sentencia de Nicolás de Soto y Gabriel Álvarez Abarca, que de nuevo declaraban inhábil al médico de Laredo, aunque luego volvieron a evaluarlo y lo aprobaron. De haber procedido colegiadamente, un solo fallo de uno de sus miembros hubiese bastado y se habrían inhibido los restantes componentes del tribunal ${ }^{11}$.

La primera legislación valenciana que reguló la sanidad fueron sus Furs, otorgados por Alfonso el Benigno en las Cortes de 1329-30. El título universitario para los físicos y el examen por el municipio de los profesionales, incluidos cirujanos, barberos y apotecarios, fueron las principales formas de control. Aspectos estos ya contemplados

9 González ArCE, «Los proyectos de ordenanzas», pp. 209-212.

10 AGS, RGS, 1475-04, 425; 1475-07, 537. Campos Díez, El Real tribunal, pp. 29-31; Amasuno SÁrraga, Medicina ante la ley, pp. 117-118. Como en este reinado las alcaldías de los médicos y cirujanos las ejercían las mismas personas, generalmente los galenos reales, cuando en 1477 fue nombrado como cirujano de la reina Isabel Gonzalo Andújar, tras el deceso de maestre Álvaro Martín, no se le hizo al tiempo alcalde mayor de esa especialidad (AGS, RGS, 1477-08, 412).

11 AGS, RGS 1495-01, 240; 1496-10, 352. 
por Jaime I para Montpellier, en 1272, en el caso de los médicos ${ }^{12}$. En Cataluña, los antecedentes del Protomedicato los encontramos en el encargo de 1337 de Pedro el Ceremonioso a un médico y un cirujano, sin nombramiento oficial, para que castigasen a quienes ejerciesen la medicina sin título. En 1444, Alfonso V designó como protomédico a su «arquiatra» personal, seguramente por influencia italiana. Desde entonces este cargo se fue implantando en el resto de los reinos peninsulares ${ }^{13}$. Antes de su aparición, el Colegio de médicos de Barcelona, fundado en 1342, desempeñó estas labores de fiscalización ${ }^{14}$. Como en Aragón, donde el control sobre los sanadores correspondió también a los colegios de médicos, cirujanos y boticarios, hasta que en 1592 fue creado el Protomedicato, que pasó a ocuparse de los espacios que escapaban a la supervisión del Colegio de Zaragoza ${ }^{15}$. Caso similar al de Navarra y la cofradía de San Cosme y San Damián, de Pamplona, aparecida en 1496, relevada en sus labores evaluadoras tras la implantación del Protomedicato, en $1525^{16}$.

\section{La paulatina pérdida de COMPETEnCias CONCEJILES}

Las facultades examinadoras, inspectoras y judiciales de los alcaldes mayores iban en contra de las competencias concejiles. También fueron en detrimento de las atribuciones jurisdiccionales de los jueces ordinarios, a los que a partir de entonces se apartó del conocimiento de las causas concernientes a estos profesionales. De este modo, en tiempos de Juan II, la mayor parte de los concejos se negaron a aceptar esta intromisión, pues consideraron que quebrantaba sus fueros y privilegios. Así, por ejemplo, el de Murcia los rechazó alegando exclusivas competencias en la materia. Para ello recurrió a la concesión enriqueña que permitía que las disposiciones reales consideradas antimorales fuesen obedecidas pero no cumplidas, es decir, aplazadas indefinidamente. De manera que continuó con la designación de tribunales municipales para examinar a médicos y cirujanos, a los que luego expedir licencias.

Comenzó así un período de disensiones entre algunos ayuntamientos y los examinadores que pretendían hacer efectivo su nombramiento, por lo que al principio no se alcanzaron los resultados deseados. En este fracaso inicial influyó sobre todo la venalidad de los cargos y la consiguiente corrupción. En las Cortes de Zamora de 1432 las ciudades

12 García Ballester, Luis. «Panorama de la medicina en una sociedad medieval mediterránea: la Valencia cristiana bajomedieval». Dymanis, 1987-1988, vol. 7-8, pp. 60-66. Gallent Marco, Mercedes. «Médicos y cirujanos mudéjares en el reino de Valencia». Saitabi, 2009, vol. 59, pp. 83-86.

13 Danón y Bretos, Josep. «Protomédicos y Protomedicato en Cataluña». Dymanis, 1996, vol. 16, p. 205.

14 García Ballester, Luis. "Los orígenes de la profesión médica en Cataluña: el "colegium” de médicos de Barcelona (1342)». En Estudios dedicados a Juan Peset Aleixandre. Valencia: Universidad de Valencia, 1982, vol. II, pp. 129-149.

15 Fernández Doctor, Asunción. «El control de las profesiones sanitarias en Aragón: el Protomedicato y los Colegios». Dymanis, 1996, vol. 16, pp. 174-176.

16 Sánchez Álvarez, El Protomedicato navarro, pp. 39-46, 58. Serrano, Francisco. Medicina y enfermedad en la corte de Carlos III el Noble de Navarra (1387-1425). Pamplona: Gobierno de Navarra, 2004. 
JOSÉ DAMIÁN GONZÁLEZ ARCE

LOS MUNICIPIOS CONTRA EL CENTRALISMO MONÁRQUICO. LA OPOSICIÓN CONCEJIL

A LOS ALCALDES MAYORES DE LAS PROFESIONES SANITARIAS EN LA CASTILLA DEL SIGLO XV

protestaron contra los alcaldes de físicos, cirujanos y barberos, que atentaban contra sus privilegios, y pidieron que no actuasen, ante lo que el rey prometió que no ejercerían sin su especial mandado, para lo que daría sus cartas. No obstante, los examinadores consiguieron nuevas misivas que les facultaban, lo que motivó otra queja en las Cortes de Madrid, de 1435. Malestar que resurgió en las de Madrigal, de 1438, donde acusaron a los alcaldes y a sus lugartenientes de aprobar a personas inhábiles, si bien las ciudades cedieron parcialmente y aceptaron que realizasen los exámenes, aunque en presencia de la justicia municipal o de los regidores concejiles. Fue una victoria temporal del centralismo monárquico, pues la caída de Álvaro de Luna, el valido inspirador, supuso la vuelta a una mayor autonomía concejil y, por tanto, a los exámenes municipales ${ }^{17}$.

\subsection{Murcia}

Como ciudad periférica y lejana al poder central, tal vez Murcia fuese la que más se resistió a aceptar la pérdida de competencias exclusivas sobre su sanidad local, y la que más éxito tuvo, pues no fue hasta bien entrado el reinado de los Reyes Católicos cuando los alcaldes mayores lograron imponer su autoridad.

En 1390 el concejo nombró a un médico como veedor para hacer cumplir las ordenanzas urbanas a físicos y boticarios. En 1409, David Damasco, maestro en dolencias oculares, compareció ante el consistorio junto a otros judíos, el cirujano Mayr Axarques y el boticario Cohen, para solicitar ser examinado por los cirujanos en el arte de sanar ojos. La evaluación tuvo lugar ante los regidores según las preguntas pertinentes, que el candidato superó. De manera que, como anteriormente había realizado buenas curas, fue dado por buen maestro y el ayuntamiento le otorgó la licencia. Un procedimiento similar se siguió en 1411 con el aspirante a cirujano maestro Juan. Meses después, designó como «veedor para ver las cosas e medeçinas que los boticarios han de dar para los paçientes de la dicha çibdat, para ver sy aquellos que las dan sy son tales como deuen», al boticario Alfonso Yáñez Cohen, para que, junto con los jurados concejiles, juzgase en dicho oficio. En 1417 llegó el doctor González de Llenera, maestro en el arte de la física, que se prestó a ejercer tras superar el examen en la catedral, ante el cabildo catedralicio, otros letrados y frailes dominicos y franciscanos, para lo que solicitó un salario de la ciudad. En 1419 comparecieron ante los regidores Diego Alfonso, bachiller en medicina, Alfonso Yáñez, Mayr Axarques y Moisés, físico, quienes presentaron a Juan Montagud, tendero vendedor de especias, que aspiraba a ser apotecario con licencia municipal; de manera que los susodichos lo habían «examinado e interrogado de las cosas que requerían a la çiençia de la boticaría» y, como lo hallaron capacitado, solicitaron, y obtuvieron, la citada licencia. En 1421 el alcalde mayor Diego Rodríguez, «que se dice de los cirujanos», nombró como su lugarteniente y le otorgó poder cumplido al bachiller Francisco López, para que, en

17 Torres Fontes, Juan. «Los médicos murcianos en el siglo XV». Miscelánea Medieval Murciana, 1973, vol. 1, pp. 215-217; Campos Díez, El Real tribunal, pp. 26-28; Amasuno Sárraga, Medicina ante la ley, pp. 82-87; Cortes de los antiguos reinos de León y de Castilla. Madrid: Real Academia de la Historia, 1866, vol. 3, pp. 139-140, 225-226, 317-318. 
los obispados de Toledo, Jaén y Cartagena efectuase en su nombre los exámenes de los aspirantes, salvo si ya habían sido evaluados por el propio Rodríguez o por su compañero Ávila ${ }^{18}$.

De este siglo xv tenemos otros exámenes de médicos, cirujanos y barberos. Pruebas realizadas por los frailes dominicos o franciscanos, por sus conocimientos de Filosofía y Teología, aunque no contaran con muchos de Medicina, junto a algunos galenos y cirujanos locales, generalmente judíos. El lugar solía ser la sala de juntas consistoriales, ante las autoridades urbanas. Las preguntas versaban sobre Filosofía y, a veces, Teología y Astrología; mientras que a los cirujanos se les exigían también ejercicios prácticos. Tras superar la evaluación, el concejo emitía un testimonio escrito con el nombre de los examinadores y el acuerdo municipal que declaraba la aptitud del candidato, y le facultaba para el ejercicio de la profesión en la ciudad y su término. Tal y como ocurrió con el judío Samuel Aventuriel, que alegó ser sabedor de las artes de lógica, filosofía y medicina, por lo que solicitó, en 1428, ser examinado para poder practicar como maestro sin caer en sanción alguna; posteriormente, en 1429, tras reclamarlo repetidas veces, obtuvo un sueldo de 800 mrs. anuales, como los restantes galenos concejiles. En 1449, el físico judío maestre León solicitó del consistorio su carta de examen. En ella consta que además de conocedor de las artes anteriores, también practicaba la astrología. En 1464 el ayuntamiento ordenó dar la de cirujano al judío Yusuf Absarga, aunque parece que la prueba la realizó en solitario el doctor en medicina y cirugía maestre Jaime de Limiñana. La licencia sería válida en el alfoz murciano, aunque en ella se solicitaba del rey y de otros municipios que la aceptasen y dejasen trabajar al interesado en ellos. Este mismo examinador aprobó en 1465 a un pariente del anterior, igualmente como cirujano, David Absarga, hijo del también cirujano Moisés Absarga. En 1468, se prohibió al ensalmador Galcerán que practicase la cirugía hasta que fuese examinado en público concejo por maestros cirujanos y físicos; mientras tanto podía seguir con su actividad de componedor de huesos rotos o dislocados ${ }^{19}$.

Como vemos, la potestad evaluadora local se mantuvo intacta a pesar de la aparición de los examinadores mayores reales, pero no por mucho tiempo.

En 1452, Lope Gutiérrez de Melgar, barbero de Juan II y alcalde y examinador mayor de esta especialidad, nombró como su lugarteniente en Murcia al cirujano local Alfonso López de Varea. La respuesta concejil fue emitir una ordenanza que castigaba con 150 mrs. a quienes afeitasen los sábados por la noche o las fiestas de guardar. Como entre las atribuciones del delegado estaría la de sancionar estas prácticas, con este gesto el consistorio las ignoraba de manera facticia, pues dicha multa sería repartida entre el denunciante, las obras de reparación de las murallas urbanas y la cofradía de Santa

18 AMM, AC, 1408-09, fol. 275r-v; 1410-11, fols. 134r-v, 153v; 1417-18, fol. 26r; 1418-19(bis), fol. 68r. González ArCe, José Damián. Los gremios medievales de Murcia. Organización y estructura del artesanado urbano en el modo de producción feudal, Tesis doctoral. Murcia: Universidad de Murcia, CD-rom, 1998, p. 60; Amasuno Sárraga, Medicina ante la ley, pp. 78-79.

19 AMM, AC 1427-28, fols. 57v-58r; 1429-30, fol. 35v; 1449-50, fols. 21v-22v; 1464-65, fols. 72v-73r; 1465-66, fols. 39v-40r; 1468-69, fol. 31r-v. Torres FonTes, «Los médicos murcianos», pp. 13, 211-212, 219, 255-267. Sobre los exámenes realizados por el ayuntamiento de Valencia, García BaLLESTER, «Panorama de la medicina», pp. 79-85. 
JOSÉ DAMIÁN GONZÁLEZ ARCE

LOS MUNICIPIOS CONTRA EL CENTRALISMO MONÁRQUICO. LA OPOSICIÓN CONCEJIL

A LOS ALCALDES MAYORES DE LAS PROFESIONES SANITARIAS EN LA CASTILLA DEL SIGLO XV

María de la $\mathrm{O}$, sin que él percibiese nada. En 1459 era el barbero murciano Gonzalo de Toro, que presentó una carta de poder por la cual los examinadores mayores, Muńoz y Gutiérrez, delegaban en él su lugartenencia en el reino de Murcia, excepto en Lorca. En 1461 el ayuntamiento nombró a los cirujanos locales, maestre Benito López de Pulido y Juan de Merlo, como veedores del oficio, para que actuasen junto al susodicho; nadie podía ejercer sin ser examinado por ellos. En 1476 Toro renovó su lugartenencia y mostró otra carta como examinador de barberos y flebotomianos del obispado de Cartagena, dada por el nuevo alcalde mayor, Rodrigo de Lunar. Tras ello le fue tomado juramento por el consistorio sobre que no consentiría practicar de sangrador a nadie que no entendiese que estaba capacitado. En 1490 era el barbero murciano Guillén Baster el nuevo delegado. El ayuntamiento emitió una autorización para que pudiese actuar como tal en todo el obispado. Finalmente, en 1510 se aprobaron unas ordenanzas locales que regulaban el oficio, en las que se prohibía desempeñarlo sin licencia de los alcaldes mayores, bajo multa de 1.000 mrs. para la cámara real ${ }^{20}$.

En 1478 el concejo dispuso que ningún físico ni cirujano judío trabajase sin estar examinado, so pena de $10.000 \mathrm{mrs}$., lo que implica que se seguía ignorando la potestad de los alcaldes mayores. Tales profesionales sí podían curar ojos sin pasar dicha prueba. Sin embargo, en 1488 acató expresamente la prohibición real de que los judíos laborasen de boticarios y fijó una multa de 10.000 mrs. para quienes la incumpliesen. Todavía en 1492 había cirujanos que curaban sin haber superado la evaluación, de manera que encargó a un regidor que averiguase qué ordenanza se debía aplicar al respecto. Luego demandó del escribano concejil un listado con todos los cirujanos locales para el pesquisidor y que les comunicase que en 5 días se presentasen ante el consistorio para ser examinados. En 1495 era recibida en Murcia una carta de Nicolás de Soto mediante la que designaba como sus promotores fiscales a su criado, Pedro Gómez de Frayagüe, y a Juan de Tapia, de Alcalá de Henares, con la facultad de que pudiesen citar ante su persona a los profesionales sanitarios, acusarlos y demandarlos por todo tipo de delitos, así como prohibir ejercer a quienes careciesen de licencia hasta que se presentasen ante dicho alcalde mayor. En 1501 nos encontramos con una de las pocas actuaciones conjuntas de algunos de los examinadores mayores, Soto, Gutiérrez y Fernández de Guadalupe, la designación del murciano, bachiller en medicina, Juan de Merlo, para que en el reino de Murcia sancionase en su nombre y con 3.000 mrs. a quienes ejerciesen sin estar examinados, inspeccionase las boticas, especierías y droguerías, y castigase los fraudes; se le prohibió expresamente realizar exámenes y debía remitir a los no evaluados ante los citados alcaldes. El mismo día los susodichos emitieron otra carta nombrando como su promotor fiscal a Frayagüe, en este caso de los tres a la vez, en el obispado de Jaén y reino de Murcia; las acusaciones en el primero las haría ante el bachiller Juan Rado y el físico Luis, mientras que en el segundo, también ante Rado y el antedicho Merlo, delegados de los protomédicos. Frayagüe, asimismo, podía nombrar lugartenientes que citasen y emplazasen en su nombre, «ante los dichos juezes», a los infractores. En 1508,

20 AMM, CR 1453-1478, fols. 85r-86v. AMM, AC 1452-53, fol. 45r-v; 1459-60, fols. 25v-26r; 1461-62, fols. 19r, 20v-21r; 1476-77, fol. 59r; 1490-91, fol. 55v; 1509-10, fol. 28r. Amasuno SÁrraGA, Medicina ante la ley, pp. 108-110. 
JOSÉ DAMIÁN GONZÁLEZ ARCE
226 LOS MUNICIPIOS CONTRA EL CENTRALISMO MONÁRQUICO. LA OPOSICIÓN CONCEJIL
A LOS ALCALDES MAYORES DE LAS PROFESIONES SANITARIAS EN LA CASTILLA DEL SIGLO XV

por fin, se presentó ante el consistorio murciano un profesional aprobado directamente por un alcalde mayor. Se trató del apotecario Alonso de Alves, vecino de Almansa, quien mostró una carta de examen de Fernando Álvarez Abarca, o de la Reina, intitulado como alcalde y examinador mayor de todos los físicos, cirujanos, boticarios... y «oculistas» (sic), y pidió ejercer en la ciudad, a lo que se accedió, pero siempre que se atuviese a las ordenanzas locales. El aspirante manifestó ante Álvarez haber estudiado y practicado de boticario durante mucho tiempo con sabios y famosos maestros, dijo saber que no podía ejercer sin ser examinado por el citado doctor, o quien tuviese su poder, y pidió ser evaluado. El protomédico lo interrogó sobre medicinas simples y compuestas, las yerbas y sus modos, así como sobre las confecciones, letuarios, ungüentos, emplastos, etcétera; lo dio por hábil y le hizo entrega de su carta de examen y licencia. Al ańo siguiente, el concejo prohibió trabajar a los médicos y boticarios que no tuviesen el grado en medicina o hubiesen sido aprobados "por juez conpetente», so pena de 10.000 mrs., a repartir entre el acusador, la obra del azud y los regidores ejecutores, sin que en ella participasen los alcaldes mayores o sus delegados. En caso de contumacia, el castigo sería el destierro por un ańo. De 1515 se conserva una carta de examen expedida por los protomédicos a un cirujano murciano ${ }^{21}$.

Algo similar ocurrió en la cercana Lorca. En 1504 fue denunciado ante su concejo que algunos cirujanos locales practicaban la medicina y recetaban purgas, medicamentos y sangrías. Por ello se les ordenó que mostrasen los títulos mediante los cuales curaban de cirugía y medicina; dos lo hicieron con sus cartas de examen y se les prohibió ejercer de galenos, bajo pena de muerte ${ }^{22}$.

\subsection{Sevilla}

La capital hispalense constituye un caso intermedio. Como Murcia, ofreció una resistencia inicial a los alcaldes mayores, pero, al ser la mayor ciudad del reino y estar fuertemente sometida al poder central, esta actitud no se pudo mantener, de manera que ya con Enrique IV veremos actuar a dichos delegados plenamente.

En 1434 Juan II remitió una carta al concejo de Sevilla en la que le exponía cómo en las Cortes de Zamora de 1432 había suspendido las alcaldías mayores de los oficios sanitarios humanos y animales. Sin embargo, su médico real y examinador mayor, el doctor Diego Rodríguez de Santa Cruz, protestó porque no eran obedecidos ni él ni sus delegados por los físicos, cirujanos y boticarios de la Corona, que apelaban a la antedicha suspensión; porque los ejecutores hispalenses habían quitado a los alcaldes puestos por el susodicho en la ciudad; y porque el consistorio sevillano había nombrado sus propios alcaldes y examinadores, para que en su nombre evaluasen y juzgasen a los cirujanos. A lo que el monarca contestó disponiendo que la suspensión de las Cortes no afectase

21 AMM, AC 1478-79, fol. 31r; 1487-88, fol. 89r; 1492-93, fol. 24v, 26r; 1507-09, fol. 35v; AMM, CR 1494-1505, fols. 160r-163r; 1505-1514, fols. 33v-34r. GonZÁLEZ ArCE, Los gremios medievales, pp. 141142, 168; Amasuno Sárraga, Medicina ante la ley, pp. 158, 175-180.

22 Archivo Municipal de Lorca, AC 1504-05, fol. 22r. 
JOSÉ DAMIÁN GONZÁLEZ ARCE

LOS MUNICIPIOS CONTRA EL CENTRALISMO MONÁRQUICO. LA OPOSICIÓN CONCEJIL

A LOS ALCALDES MAYORES DE LAS PROFESIONES SANITARIAS EN LA CASTILLA DEL SIGLO XV

a Rodríguez de Santa Cruz ni a sus lugartenientes, pues había sido nombrado como alcalde mayor vitaliciamente. De manera que ordenó al ayuntamiento que consintiese al mismo y a sus delegados seguir con sus labores. Si bien añadió que los galenos que debían ser examinados en la corte real por el antedicho y por el doctor Martín González de Lucena, también médico real y alcalde y examinador mayor, podían serlo igualmente si solo estaba presente uno de ellos. Pero no cabía la posibilidad de que la prueba la hiciese uno de sus representantes. Tras superarla, al evaluado se le expediría una carta de examen firmada por los mencionados doctores, sin la cual no se podía ejercer la medicina en el reino. Además, el rey mandó a Sevilla que los alcaldes designados por su ayuntamiento no pudiesen actuar como tales, pues en adelante todos los alcaldes locales debían ser examinados y aprobados por los dos mayores, tras jurar que actuarían correctamente y no cometerían cohechos. Cuatro años después, en 1438 Santa Cruz volvió a protestar porque el concejo hispalense no había querido obedecer la misiva anterior, y mantenía a los alcaldes y examinadores locales de los físicos, cirujanos, boticarios y enfermos de lepra. De manera que el soberano ordenó nuevamente su cumplimiento, que se recibiese al acalde mayor y a sus factores y que se revocasen las alcaldías locales.

Posteriormente, en ese mismo 1438, Santa Cruz emitió una carta de poder en favor del maestro sevillano Manuel Romí, doctor en medicina, para que en su nombre actuase como alcalde y examinador de los médicos, apotecarios, especieros y cuidadores de leprosos de Sevilla y su arzobispado, a los que podía impedir ejercer si no estaban examinados o no los encontraba capacitados. También podía presentar ante las autoridades correspondientes el levantamiento real de la suspensión hecha en las Cortes de Zamora, que por tanto no le afectaba a él ni a sus delegados. Cosa que así hizo, de modo que mostró tales documentos ante el concejo de Jerez de la Frontera, en mayo de dicho año. El cual se mostró presto a su cumplimiento porque el tal Romí era "vno de los más famosos dotores en mediçina deste regno». Por su parte, este juró usar su oficio leal y derechamente, sin percibir nada más allá de sus correspondientes honorarios. Más adelante, Santa Cruz volvió a emitir otra carta de poder, ahora para Pedro Flores, bachiller en artes y medicina, criado del «excelente» doctor en medicina Juan Fernández de Salamanca, difunto médico real, para que en su nombre actuase como alcalde y examinador de galenos y boticarios en Cádiz y su obispado; y, por tanto, en Jerez (donde fue aceptado, como el anterior), Lebrija, Rota, Sanlúcar de Barrameda y Arcos de la Frontera. Si bien, como luego veremos, es más que dudoso que este nuevo alcalde hubiese podido ejercer como tal en las tres últimas localidades de señorío ${ }^{23}$.

En 1447 los cirujanos sevillanos recordaron a su concejo la revocación de las alcaldías mayores de las Cortes de Zamora de 1432, por ser contrarias a los privilegios urbanos y a causa de los cohechos y prevaricaciones cometidos. Entendían que las competencias sobre la profesión habían retornado al municipio, por lo que motu proprio habían seleccionado a un hombre bueno, al cirujano Alfonso Íniguez, para actuar como juez en nombre del consistorio. Nombramiento del que solicitaron ratificación, pues lo consideraban idóneo para corregir los errores del oficio. Los regidores, sin menoscabar su derecho a designar

23 AMJF, AC, 1438, fols. 45r-47v, 48v, 105r-106r. 
a los alcaldes de los cirujanos, accedieron y le otorgaron la alcaldía vitaliciamente en la ciudad y en su jurisdicción, así como los derechos y salarios que llevase aparejados.

Sin embargo, los alcaldes mayores y sus delegados se resistieron a perder sus competencias. Días más tarde, el cirujano Diego Alfonso recordó al consistorio que el alcalde mayor, Andrés Rodríguez, y sus lugartenientes habían recibido autorización para actuar en la localidad. De manera que Alfonso, que había ejercido en vida del anterior examinador mayor, pretendía continuar tras su deceso, pues había sido confirmado en la lugartenencia por el nuevo, maestro Alfonso de Roa. Puede que por entonces hubiese en la ciudad otros dos delegados, Diego Aboacar y el antedicho maestre Manuel Romí. En 1455, Enrique IV escribió al concejo para notificarle que el cirujano Diego Rodríguez, y su hijo, el bachiller médico y cirujano Juan Rodríguez, situados por Roa como alcaldes y examinadores en todo el arzobispado de Sevilla, se temían que no les permitiesen ejercer, por lo que solicitaron amparo real. El monarca ordenó cumplir la carta de poder dada por el alcalde mayor a sus delegados. A lo que los veinticuatros (regidores) respondieron que anteriormente habían sido nombrados otros examinadores de los cirujanos por parte de los alcaldes mayores de los físicos, Gómez García de Salamanca y Juan Fernández de Soria, pero que, según la merced dada por el rey al maestro Alfonso de Roa, era este el único que podía proveer las alcaldías locales de los cirujanos y no los antedichos; así que acataron el mandato regio. Por su parte, los lugartenientes designados por los alcaldes mayores de los médicos, los asimismo cirujanos sevillanos maestre Juan Leví, Alfonso García y maestre Alfonso, recibidos como examinadores del oficio, protestaron tras conocer la aceptación de los Rodríguez, pues el ayuntamiento les había dado el cargo en exclusiva y ahora les privaba de su desempeño. El consistorio ordenó a su asesor legal, el licenciado Juan Fernández de Sevilla, que viese las cartas de nombramiento, escuchase a las partes y elevase un informe. El jurista determinó que en primer lugar habían sido nombrados como alcaldes locales Leví, García y maestre Alfonso, según poderes dados por los alcaldes mayores de los físicos de Juan II, Salamanca y Soria, luego confirmados por Enrique IV. Mientras que, posteriormente, el alcalde mayor de los cirujanos puesto por este nuevo rey, Roa, había designado a los Rodríguez. Este nombramiento no anulaba a los anteriores, y como no parecía clara la voluntad real, el concejo debía remitir el asunto a instancias regias. Entre tanto, tenían que ser padre e hijo quienes mantuviesen la sinecura ${ }^{24}$.

He aquí un ejemplo de los cohechos y prevaricaciones perpetrados por los alcaldes mayores que llevaron a su suspensión por las Cortes, esto es, la venalidad de los cargos de delgados locales, que nombraban sin orden ni concierto y a veces sin tener competencias.

Si durante la primera parte de su reinado, cuando gozó de mayor autoridad, Enrique IV tuvo problemas para que los municipios aceptasen a los alcaldes mayores y a sus delegados, como acabamos de ver, mayores habrían sido estos en la última, cuando las continuas guerras civiles y sucesorias propiciaron que muchos de ellos se apartasen de la obediencia real. Así se explica que Jerez de la Frontera, a la que hemos visto aceptar a los lugartenientes de los examinadores reales, recobrase parte de estas competencias hacia

24 Archivo Municipal de Sevilla (AMS), AC 1447, sep.-dic., fols. 64v-65r, 73v; 1455, ago.-oct., fols. 34, 71r-72r, 91v-92r; 1455, oct.-dic., fols. 11v-12r. Amasuno Sárraga, Medicina ante la ley, pp. 106-107. 
JOSÉ DAMIÁN GONZÁLEZ ARCE

LOS MUNICIPIOS CONTRA EL CENTRALISMO MONÁRQUICO. LA OPOSICIÓN CONCEJIL

A LOS ALCALDES MAYORES DE LAS PROFESIONES SANITARIAS EN LA CASTILLA DEL SIGLO XV

1462. Año en el que un galeno fue denunciado ante su concejo, al que solicitó ser evaluado. Este acordó llamar a los cirujanos y físicos locales, así como al alcalde Pedro Martínez de Sanabria, "que era jues dellos» (por el contexto parece más un alcalde municipal que un delegado de los alcaldes mayores), para que viesen si el susodicho era suficiente para usar del oficio. Quienes, tras preguntarle por asuntos de la profesión y las curas que había realizado, le pidieron sus cartas de examen; por lo que les hizo entrega de 7 documentos, 2 de ellos en pergamino y latín, y los otros en romance. Este asunto levantó fuertes disensiones tanto entre los evaluadores como entre los regidores concejiles. Meses más tarde, el acalde local de los físicos y boticarios, Martínez de Sanabria, solicitó del consistorio que regulase la confección de medicinas, para evitar fraudes y engaños, y que se prohibiese a los médicos ejercer de apotecarios y viceversa. A lo que los regidores respondieron que tales extremos serían consultados con los alcaldes mayores reales, lo que significa que estos todavía gozaban de cierta aceptación ${ }^{25}$.

En 1491 fueron los barberos sevillanos los que actuaron contra sus alcaldes. Denunciaron ante el concejo que los de la ciudad y su tierra, Juan de Medina y Pedro Rodríguez de Valderramabarberos, situados por los mayores, Lunar y Palacios, les exigían sanciones tras acusarlos indebidamente de afeitar los sábados y las noches de algunos festivos. Actuaban como juez y parte interesada, porque se beneficiaban de las multas que imponían, sin que pudiese haber apelaciones de sus sentencias, pues supuestamente los Reyes Católicos habían ordenado a las justicias del reino inhibirse en los asuntos que tratasen. En 1496 Lunar y Palacios revocaron las lugartenencias de Medina y Valderramabarberos, de manera que debían retirar las armas reales de las puertas de sus tiendas. A lo que los interesados no hicieron mucho caso, pues al año siguiente, 1497, Medina, al que todavía se denomina como «baruero alcallde e examinador mayor de los barueros e flomotamianos desta çibdad de Seuilla e su arçobispado por los barueros mayores del rey e de la reyna», firmó un testimonio, a petición de un alfajeme de Carmona, sobre cómo en la capital se afeitaba en público ${ }^{26}$.

Los alcaldes mayores de los médicos procedieron en 1478 contra un tal promotor de los especieros y boticarios de la ciudad. En 1491 Juan Rodríguez de Toledo situó como examinador local a Bartolomé de Carvajales, lo que no gustó a los profesionales sevillanos y obligó a intervenir al concejo al año siguiente ante los soberanos, que revocaron el nombramiento. Si bien, posteriormente, a instancias de Toledo, Guadalupe y Soto, designaron al licenciado Flores como su delegado para supervisar las boticas. A final de siglo, la potestad de los examinadores mayores se hallaba tan asentada que pudieron ocuparse incluso de la supervisión de los oficios menores relacionados con la sanidad. Así, en 1500 varias parteras jerezanas «e otras mugeres que curan de enfermedades secretas de otras mugeres» manifestaron ante su concejo que habían sido convocadas por los

25 AMJF, AC 1464, fols. 112r-v, 226r.

26 De 1471 son las ordenanzas del arte de la flebotomía y sacamuelas, que contienen la prohibición de trabajar sin estar examinado por los alcaldes gremiales. En 1503 un boticario examinado de Carmona solicitó del concejo que evaluase a un empleado para ampliar su negocio y tener mejor provista su apoteca (AMS, AC 1471, jun.-jul., fol. 48r-v; 1491, abr.-ago., fols. 11v-12r. Archivo Histórico Provincial de Sevilla, protocolo 3.216, fol. 1r-v. Archivo Municipal de Carmona, AC 1497, fol. 159; 1503, fol. 152). 
doctores reales en Sevilla, Julián, Soto y el licenciado de Guadalupe, para ser examinadas de sus oficios; cosa que nunca antes había ocurrido. Además, algunas de ellas eran viejas, estaban mal de salud, eran pobres o se hallaban ocupadas atendiendo a mujeres principales y a otras más corrientes y, si partían, las preñadas y parturientas podrían quedar en peligro. Por lo que solicitaron que el consistorio escribiese a los protomédicos para que enviasen a Jerez a un delegado para efectuar la evaluación, o que esta ciudad designase al examinador. La respuesta fue que una de tales profesionales llevase dicha carta a Sevilla, pues debían ser examinadas por ellos o por algún diputado suyo. A lo que las primeras contestaron que la misiva la portase el procurador síndico jerezano. Por su parte, los alcaldes mayores alegaron que, según disposiciones reales, las pruebas las debían hacer ellos mismos en persona, de manera que las comadronas que contasen con licencias de partera las remitiesen a la capital hispalense para que fuesen revisadas y confirmadas; mientras que las que no las tuviesen tendrían que acudir en persona; pero, para evitar la desatención, lo podían hacer por turnos. Además, había dos mujeres que ejercían de físicas, la Andina y la de Canelas, y con más motivo había que averiguar cómo actuaban y cuáles eran sus conocimientos de medicina.

En 1501 Miguel Pérez Aragonés, juez de los físicos de Sevilla, puesto por los alcaldes mayores para «esaminar e castigar» a los médicos, cirujanos, boticarios, herbolarios y los lazaretos, cuando estuvieron en la capital andaluza, fue denunciado por haber cometido abusos. Previamente a esta designación, Aragonés, sevillano de San Salvador, fue médico del duque de Medina Sidonia y su alcalde examinador de todos los físicos, cirujanos y boticarios de sus señoríos. Una especie de alcaldía mayor del ducado con potestad, como las reales, para situar lugartenientes. Lo que hizo en 1499 con el bachiller médico Francisco de Guillén, vecino de Villanueva de Barcarrota, para que fuese al condado de Niebla, perteneciente al duque, a pedir cuentas y razón a todos los profesionales sanitarios, comprobar si eran maestros examinados en sus respectivas artes, exigirles el correspondiente título y sancionarlos con las multas que estimase pertinentes. También revocó cualesquier otros poderes dados anteriormente. Resulta evidente que, a pesar de que en los nombramientos se habla de una jurisdicción universal, tanto en el realengo como en los señoríos, incluidos los eclesiásticos, las competencias de los protomédicos no eran efectivas en estos, al menos no de hecho en los de los aristócratas más poderosos, que contaban con sus propios alcaldes mayores. Caso del marqués de Cádiz, cuyo barbero, Martín López, fue alcalde de todas las tierras de la casa de Arcos. Este, en 1484, dio una autorización a Gonzalo de Morales para ejercer el oficio de barbero y flebotomiano en la ciudad de Arcos de la Frontera, en la cual actuaría como alcalde de los alfajemes locales y podría prohibir trabajar a los maestros que estimase no eran competentes. Así se entiende que, en 1494, el gobernador de Pastrana, perteneciente a la orden de Calatrava, en ese momento bajo jefatura real, apresase a los delegados del doctor de la Reina (Gabriel Álvarez Abarca), a su criado Anselmo Pérez y a Francisco de León, allí enviados para visitar a los profesionales locales. Un caso parecido se dio en 1514, con Pedro de Frías, en el adelantamiento de Cazorla ${ }^{27}$.

27 AMS, Privilegios, carpeta 174, n. ${ }^{\circ}$ 20; AMJF, AC 1500-05, fols. 20r, 31v-32r; AMJF, Protocolos, n. ${ }^{\circ}$, fol. 158v. Amasuno Sárraga, Medicina ante la ley, pp. 147-156, 166-167. 
JOSÉ DAMIÁN GONZÁLEZ ARCE

LOS MUNICIPIOS CONTRA EL CENTRALISMO MONÁRQUICO. LA OPOSICIÓN CONCEJIL

A LOS ALCALDES MAYORES DE LAS PROFESIONES SANITARIAS EN LA CASTILLA DEL SIGLO XV

Igualmente, papel mojado parecen las disposiciones de 1494 y 1498 que revocaron las lugartenencias y prohibieron conceder otras nuevas, pues la de Pérez Aragonés fue ganada en 1501. Aunque en 1514 los protomédicos de la Reina y de la Parra otorgaron poder cumplido al doctor Bernardino Suárez, de Guadalajara, para llamar a su presencia a todo tipo de sanadores y requerirles los títulos que los facultaban, y a los que no los tuviesen multarlos con 3.000 mrs., hasta que fuesen examinados por ellos; también podía cerrar sus tiendas y quemar sus medicinas, pero sin evaluar a ninguno, sino remitirlos a los susodichos examinadores mayores ${ }^{28}$.

\subsection{Otros municipios}

Las escuetas noticias conservadas de otras localidades las sitúan entre la resistencia a ultranza, al estilo de Murcia, como ocurrió con Burgos, y la de tipo más formal que efectivo, como la sevillana, seguida en Toledo.

En Burgos nadie podía practicar la medicina sin ser aprobado por el concejo. En 1450 fue contratado maestre Martín, doctor en medicina, por 10 años; que bien pudo ser el anterior alcalde mayor Martín de Cabañas. El nuevo galeno municipal aprovechó para denunciar que algunos físicos y boticarios ejercían incorrectamente, por lo que el consistorio ordenó que ninguno de los médicos que no fuese asalariado del ayuntamiento lo hiciese sin licencia del susodicho y de la propia ciudad, so pena de $10.000 \mathrm{mrs}$. y, si se resistía, de 60 azotes. En 1493 dispuso que aquellos que trabajasen sin examen de médico o cirujano, o sin mostrarlo al concejo, podían ser condenados a muerte. La prueba debía ser verificada por los físicos licenciados locales, ante las autoridades del lugar. Todavía en 1494, a pesar de las alcaldías mayores, mandó a varios profesionales no sanar hasta comprobar su suficiencia. Meses más tarde prohibió a los boticarios aceptar las recetas de algunos que se decían médicos. El ayuntamiento también actuó sobre las apotecas. En 1484 nombró para supervisar cada 4 meses los materiales y la habilidad y suficiencia de los apotecarios a algunos de sus componentes, asesorados por dos médicos licenciados. En 1489 cerró la botica de maestre García, por usar de médico sin ser hábil, al tiempo que le vedó ejercer la medicina y la cirugía ${ }^{29}$.

En un primer momento Toledo, como otros municipios, se opuso a las alcaldías mayores de los físicos. Entre 1450-1456 aprovechó la gran afluencia de sanadores judíos que no estaban examinados para establecer que no curasen sin ser evaluados por las personas nombradas por el concejo, so pena de 1.000 mrs. para las murallas. Excusa que le permitió exigir el examen a todos los profesionales locales, que debían comparecer ante el ayuntamiento para ser dados por aptos; lo que también hizo con los boticarios.

28 AMM, CR 1505-1514, fol. 170r-v.

29 Archivo Municipal de Burgos (AMB), AC 1450, fols. 79r, 89v-90r; 1488, fol. 178v; 1489, fols. 238v-239r; 1491, fol. 65r; 1493, fol. 84v; 1494, fols. 32r-v, 180v; Bonachía Hernando, Juan Antonio. «La ciudad de Burgos en la época del Consulado. (Apuntes para un esquema de análisis de Historia Urbana)». En Actas del V centenario del Consulado de Burgos. Burgos: Diputación de Burgos, 1994, p. 135. Amasuno Sárraga, Medicina ante la ley, pp. 103-104. 
Más adelante se atemperó esta resistencia, y en 1498 solamente protestó ante Isabel y Fernando porque Julián Gutiérrez, en contra de sus privilegios, había actuado como alcalde mayor sin la autorización expresa de los soberanos, y porque sancionó a ciertos sanitarios sin mostrar el citado permiso y sin estar presentes un regidor y un jurado. En 1509 el consistorio volvió a quejarse contra el citado protomédico, en este caso ante Juana I, por la redacción de unas ordenanzas en las que prohibía la exportación de conservas y confites sin su autorización. Ya en 1515 aceptó plenamente a Antonio Benavente como promotor fiscal de Gutiérrez ${ }^{30}$.

Como en Sevilla, también en la Córdoba de los Reyes Católicos los alcaldes mayores impusieron prontamente su autoridad. En 1478 revocaron la alcaldía local del licenciado Juan Rodríguez de Santa Cruz, vecino de la ciudad, probablemente nombrado en tiempos de Enrique IV como alcalde de Sevilla, visto más arriba. No obstante, el concejo no cedió del todo sus competencias, de manera que todavía en 1496 dispuso que junto a «los alcalldes de los médicos y çirujanos» (hemos de entender que eran los «mayores»), debían actuar en los exámenes de los profesionales y de los medicamentos el bachiller Oliva y algunos delegados de los regidores. En 1503, ante la masiva llegada de forasteros que pretendían practicar la medicina y la cirugía, mandó que Oliva y su yerno revisasen sus títulos y exámenes. Estos no intervinieron en 1505 cuando el bachiller Torreblanca presentó un poder de los protomédicos para examinar las medicinas de la ciudad, aunque junto a él también debían fiscalizarlas el alcalde mayor local y los diputados concejiles. Menos suerte tuvieron los examinadores mayores con Jerez de la Frontera, donde en 1479 quisieron delegar en el bachiller Juan Gutiérrez de Córdoba, sin que fuese aceptado, de manera que al año siguiente los monarcas hubieron de repetir este nombramiento ${ }^{31}$.

Un municipio pronto sumiso a los dictados reales y de sus veedores fue el de Ávila, pues en tiempos de Enrique IV habría aceptado como delegado de los alcaldes mayores de los médicos y cirujanos al judío Abraham Çerrulla. Madrid, que en 1487 reconoció el examen que Guadalupe realizó en persona de sus físicos, cirujanos y boticarios, sin embargo, en 1501 prohibió ejercer a quienes no fuesen examinados por el ayuntamiento, so pena de $10.000 \mathrm{mrs}$. para las obras municipales, sin tener en cuenta las disposiciones regias. En 1493, el concejo de Cuenca estableció que nadie pudiese curar sin que los alcaldes mayores lo avalasen como graduado en estudio general. En 1498 un cirujano de Ciudad Rodrigo expuso ante los Reyes Católicos que otros trabajaban en la localidad sin ser examinados; estos mandaron que nadie pudiese hacerlo sin ser graduado en estudio general o haber superado el examen de los alcaldes mayores ${ }^{32}$.

Valladolid, localidad donde la corte recalaba con asiduidad y se hallaba ubicada la Real Chancillería, no debió resistirse a la autoridad de los supervisores reales. Así se infiere de que en 1502 el consistorio dispusiese que allí no ejerciese ningún médico ni

\footnotetext{
30 Archivo Municipal de Toledo, Cajón 5, Leg. 4, n. ${ }^{\circ}$ 6; Alacena 2, Leg. 6, n. ${ }^{\circ}$ 2, fols. 123v-124r, 143r-v. Amasuno Sárraga, Medicina ante la ley, pp. 102-103, 159.

31 Archivo Municipal de Córdoba (AMC), AC 1496 (18-VII-1496); 1503 (13-III-1503, 15-III-1503, 22-III-1503); 1505 (19-II-1505). Amasuno Sárraga, Medicina ante la ley, pp. 145-147.

32 AGS, RGS, 1493-05, 11; 1498-07, 186. Amasuno Sárraga, Medicina ante la ley, pp. 142-143, $154,160-162,168$.
} 
JOSÉ DAMIÁN GONZÁLEZ ARCE

LOS MUNICIPIOS CONTRA EL CENTRALISMO MONÁRQUICO. LA OPOSICIÓN CONCEJIL

A LOS ALCALDES MAYORES DE LAS PROFESIONES SANITARIAS EN LA CASTILLA DEL SIGLO XV

cirujano sin haber sido previamente examinado. Sin embargo, no por ello este concejo perdió ciertas competencias sobre el control de la sanidad local. En 1499 acordó, para corregir los fraudes y engaños de los boticarios, llamar al médico municipal, doctor Colina, con el que convino convocar a los restantes galenos de la villa para que se juntasen con los regidores en el monasterio de San Francisco y desde allí, en parejas mixtas, visitasen todas las apotecas, para examinar las medicinas y aguas, comprobar si eran correctas y averiguar si los boticarios sabían elaborarlas convenientemente, aunque, al parecer, esta inspección no fue finalmente llevada a cabo. En 1501 fueron presentados ante los regidores y el corregidor ciertos medicamentos falsos requisados a Andrés boticario por parte de los apotecarios maestre Martín y Marcos Izquierdo, acompañados por el corregidor y el doctor Colina. Las autoridades mandaron verterlos a las puertas de la casa del infractor conforme a las ordenanzas locales. Sentencia pronunciada en presencia de los bachilleres Sancho de Salaya y Luis González, "físicos e colegiales». Del mismo modo, a otros boticarios, Juan de Santiago y Bernardo Ticarro, se les encontraron redomas, botes y barriles contrarios a la norma, que igualmente les fueron derramados ante sus inmuebles. En 1502 resultaron comisionados Antonio Franco y Francisco de San Esteban para fiscalizar los preparados que vendían los boticarios, físicos y cirujanos. $\mathrm{Al}$ año siguiente, 1503, esta labor supervisora fue mejor ejecutada. En esta ocasión los encargados de ir a catar las apotecas fueron el doctor Colina y el licenciado Sola, médicos, maestre Juan, boticario del almirante de Castilla, y el corregidor. En ellas contrastaron, además de las medicinas, los pesos y medidas empleados en su confección y dispensación. Para ello, tomaron declaraciones a sus titulares que fueron anotadas por el escribano municipal. Estos fueron los resultados:

- La tienda y botica de Gonzalo de Cuéllar no tenía las pesas pertenecientes a su oficio. Además, hallaron 2 botes con medicinas compuestas que no tenían título (indicación de su contenido); así como 3 redomas, 7 botes y 1 papel con medicamentos malos.

- La botica de Cristóbal de Carreño también adolecía de la falta de los pesos adecuados, mientras que las medidas para dispensar aguas y jarabes estaban menguadas. Asimismo, algunos botes y medicinas fueron dados igualmente por malos.

- En la de Andrés boticario, en la que estaba el apotecario Juan de Medina, y ante varios médicos, fueron declarados mal hechos ciertos medicamentos, recogidos en el registro del notario.

- En la de Sebastián de Paredes también fueron encontrados malos fámacos, del mismo modo registrados.

- En las restantes instalaciones no se descubrieron compuestos fraudulentos, excepto un ungüento porfirizado dentro de un bote, en un rincón de la tienda de Bernal boticario.

El consistorio, reunido en sesión plenaria, escuchó el informe y ordenó al merino y alcaldes quemar las pócimas falsas ante las puertas de cada boticario, así como tomarles prendas, a los primeros $5.000 \mathrm{mrs}$. a cada uno y al último 2.000 , quienes, de no encontrarles bienes muebles, raíces o semovientes suficientes para ejecutarlas, serían conducidos a la cárcel. Esta actuación desató un pleito ante las instancias reales, lo que obligó al municipio a designar a sus procuradores y representantes. Además, dispuso que la mitad de las penas 
contempladas en las ordenanzas urbanas para este tipo de actuaciones fraudulentas que tenían como destino los propios de la villa, al margen de las que iban a parar a la cámara y fisco real, fuesen en adelante para los médicos, cirujanos y boticarios encargados de inspeccionar las apotecas. Poco después era recibida una carta de los Reyes Católicos que autorizaba al concejo a registrar cuando quisiese las tiendas de los boticarios y especieros, conforme a las ordenanzas locales, y sancionar a los que actuasen contra ellas, «syn les poner en ello ynpedimento alguno los físycos de sus altezas, e que para esto no se ynpida la condición de los dichos físycos e protomédicos» (sic). Autonomía inspectora que no duró mucho, no obstante, pues en 1510 Fernando el Católico encargó al protomédico Soto que fuese a la villa a averiguar si las visitas a las boticas eran conforme a derecho. El consistorio replicó que en ausencia de dichos delegados regios sí estaba facultado para las citadas labores de supervisión ${ }^{33}$.

En 1497 el Consejo Real ordenó a los corregidores de Vizcaya y Guipúzcoa prendar al licenciado Antonio de Bilbao, que actuaba indebidamente como examinador de médicos, cirujanos, boticarios y barberos en dichos territorios. Algo similar a lo hecho en Cuenca, con Diego Núñez, y en Huete. Mientras que en 1509 fueron enviados al condado de Vizcaya el bachiller Ibasquera y Juan de Salinas, para examinar a sus físicos, cirujanos y boticarios y multar a quienes hubiesen trabajado sin la pertinente evaluación; así obtuvieron unas 2.000 doblas de oro, según denunciaron las autoridades locales. Que añadieron que por ello escaseaban los profesionales y las gentes no hallaban quién las sanase, o no tenían suficientes recursos como para permitirse los servicios de los que vivían en las villas. Los caballeros de la Junta de Vizcaya solicitaron de la reina Juana que castigase los excesos de estos delegados de los alcaldes mayores, que devolviesen las multas y que se pudiese ejercer libremente, como hasta entonces ${ }^{34}$.

En 1501, Pedro Ortiz, vecino de Segovia, tierra de barberos, como estamos viendo, fue examinado en persona por los alcaldes mayores antes de abrir su negocio. Sin embargo, los alcaldes de los alfajemes locales le tomaron una prenda hasta que los invitase a una colación, ingresase en su cofradía y observase sus ordenanzas; una clara resistencia del gremio a perder sus competencias en favor del poder central. Los soberanos determinaron que pudiese trabajar libremente, y que en adelante no se pudiesen exigir comidas ni cosa alguna por ingresar en el oficio ${ }^{35}$.

Por lo que respecta a los albéitares (sanadores de équidos) y herradores (calzadores de herraduras), el primer alcalde y examinador mayor del que tengamos constancia es Juan García, al que sustituyó su hermano, Ferrán García, vecino de Madrid, designado por Juan II tras la muerte del primero, en 1450, para juzgar todo lo tocante al oficio y

33 Archivo Municipal de Valladolid, AC 1497-1501, fols. 237r-v, 333v-334r, 362v-363r; AC 15021514, fols. 41v, 43r, 144r-147v, 495v-498v.

34 AGS, Cámara de Castilla, Pueblos, 23, 43.

35 AGS, RGS, 1501-09, 29. Amasuno Sárraga, Medicina ante la ley, pp. 159. 
JOSÉ DAMIÁN GONZÁLEZ ARCE

LOS MUNICIPIOS CONTRA EL CENTRALISMO MONÁRQUICO. LA OPOSICIÓN CONCEJIL

A LOS ALCALDES MAYORES DE LAS PROFESIONES SANITARIAS EN LA CASTILLA DEL SIGLO XV

a sus practicantes. Para ello ordenó a todos los del reino que se presentasen ante él en el plazo de 15 días, y a las autoridades locales que no se entrometiesen en su cometido. El nombramiento fue confirmado por Enrique IV, en $1467^{36}$.

Los Reyes Católicos situaron en 1475 a Francisco de Peńalosa como herrador y albéitar real, así como alcalde y examinador mayor de los herradores y albéitares de todos los reinos y señoríos, «ansý realengos commo abadengos e órdenes e behetrías ansý christianos commo judíos e moros», para que "ningund albéytar nin ferrador non pueda thener tienda nuevamente nin usar del dicho ofiçio syn primeramente ser examinados por vos». También le dieron facultad para poner en su lugar en cada ciudad un examinador, que desde entonces fueron los únicos facultados para realizar estas pruebas, y cobrar por cada una de ellas 1 dobla de la banda. Tanto el alcalde mayor como sus delegados podían igualmente pedir las cartas de examen a los albéitares para comprobar cómo habían resultado evaluados, y dar por tales a los que lo hubiesen sido con anterioridad, tras cobrarles 6 maravedís en concepto de presentación del documento y otros 6 por su confirmación. En general, dichos alcaldes, mayor y lugartenientes, debían percibir las mismas rentas que los de Juan $\mathrm{II}^{37}$.

Algunas localidades, entre ellas Sevilla, se resistieron a admitir sus competencias. En 1477, los albéitares y herradores sevillanos expusieron ante el concejo cómo en el suyo y en los restantes oficios, desde siempre, había alcaldes para examinar a quienes querían ejercerlos y abrir tienda; según las pertinentes ordenanzas, confirmadas por la Corona, que establecían que solamente los antedichos, o los alcaldes mayores, pudiesen realizar las mencionadas pruebas. Dicho lo cual, protestaron porque Peñalosa había ganado la carta de alcalde mayor y pretendía actuar sin haber presentado otra en la que los monarcas ordenasen que fuese recibido en tal puesto, sino simplemente mostrando su nombramiento a los maestros albéitares. Además, temían que personas que hasta ese momento no habían podido practicar la profesión, por inhábiles, fuesen dadas por examinadas por el nuevo alcalde mayor. De modo que solicitaron del consistorio, e indirectamente de la reina Isabel, que fuesen observadas las ordenanzas que regulaban su oficio y Peñalosa no usase allí su cargo ${ }^{38}$.

Contra las facultades exclusivas de este alcalde mayor, al año siguiente, 1478, el rey Fernando situó al albéitar sevillano, Antón Martínez, como alcalde y examinador «de todos los albéytares e ferradores desta dicha çibdad y su tierra, asý christianos, como judíos y moros en absençia de mi albéytar mayor». Ninguno podía poner tienda sin antes ser examinado por él o por sus delegados en la ciudad y en cada villa de su tierra, en número de dos o más, ya que gozaba de las mismas facultades en Sevilla que Peñalosa. Sin embargo, este se mostró agraviado, pues según su nombramiento solamente él podía examinar a los albéitares y herradores de todo el reino; la respuesta del monarca fue revocar la designación y cualesquiera otras similares ${ }^{39}$.

36 AGS, RGS, 1478-02, 39. Sobre la albeitería en la Corona de Aragón, Ferragud i Domingo, Carmel. La cura dels animals: Menescals i menescalia a la València medieval. Catarroja: Afers, 2009.

37 AGS, RGS, 1454-1475, 472; 1478-02, 39. Sobrino Сномón, Tomás. Documentación medieval del Archivo Municipal de Ávila. Vol. 2 (1436-1477). Ávila: Diputación de Ávila, 1999, pp. 119-123.

38 AMS, AC 1477, jun.-ago., fol. 70r.

39 AGS, RGS, 1478-09, 147. 
JOSÉ DAMIÁN GONZÁLEZ ARCE
236 LOS MUNICIPIOS CONTRA EL CENTRALISMO MONÁRQUICO. LA OPOSICIÓN CONCEJIL
A LOS ALCALDES MAYORES DE LAS PROFESIONES SANITARIAS EN LA CASTILLA DEL SIGLO XV

Todavía en 1486 continuaba la oposición a los alcaldes mayores, que se quejaron a los Reyes Católicos de que los herradores y albéitares locales les impedían examinar, pues alegaban contar con sus propios alcaldes, que, junto al cabildo gremial, realizaban las pruebas y entendían en su profesión, «e que aquellos que por ellos non eran exsaminados en el dicho ofiçio non podían nin deuían tener tiendas ni vsar del dicho ofiçio de albéytares e ferradores». Los monarcas dispusieron que fuesen únicamente los protoalbéitares los capacitados para poner en su nombre veedores de la profesión, y que solamente estos pudiesen ejercer de tales ${ }^{40}$.

Confirmadas sus competencias, en 1489 Francisco de Peñalosa examinaba a ciertos herradores de Zamora, a los que exigió los derechos correspondientes. Ese mismo año eran recibidos en Segovia dos examinadores del oficio ${ }^{41}$.

En 1490, al morir Peñalosa, fue sustituido por Luis de Cáceres, vecino de Valladolid, en pago a los servicios prestados a la reina, con las mismas condiciones y derechos que el anterior, pero ahora cobraría por examen 2 doblas castellanas de la banda. En 1500 una pragmática establecía que los 2 albéitares y herradores mayores vitalicios, el citado Cáceres y Diego de Zamora, no consintiesen que nadie pusiese tienda sin ser examinado por ambos personalmente, y no el uno sin el otro; aunque podían evaluar por separado, siempre que no percibiesen más de 1 dobla por el examen, lo mismo que llevarían estando juntos. Lo que uno evaluase no lo podía volver a hacer el otro. Nadie podía examinar en su lugar, ni ellos poner alcaldes que los sustituyesen. Sí estaban capacitados para demandar a los profesionales sus cartas de examen anteriores, sin cobrarles derechos. Los que trabajasen sin examen serían inhabilitados perpetuamente, condenados a pagar 1.000 mrs. para la Cámara real y otros tantos para los protoalbéitares, y perderían su tienda. Estos examinadores tenían la facultad de denunciar a las autoridades locales los fraudes y yerros, y de retener la mitad de las penas impuestas. Los trabajadores podían ser emplazados por portero o por carta dentro de las 5 leguas en torno a la corte. Ese mismo año 1500 los soberanos les dirigieron una misiva en la que les recordaban estos extremos, porque habían sido informados de que nombraban delegados que se dejaban sobornar, actuaban negligentemente y daban licencias a personas inhábiles. Tras revocar dichos nombramientos les ordenaron actuar personalmente en el examen de los aspirantes ${ }^{42}$.

Murcia también se resistió a la injerencia de los alcaldes. En 1480 su concejo nombró a tres examinadores para evaluar a todos los profesionales locales, los albéitaresherradores maestres Alfonso, Diego Morales y Rodrigo García. Quien trabajase sin superar la prueba pagaría una multa a repartir entre ellos, el acusador y los ejecutores

\footnotetext{
40 Carande, Ramón y Mata Carriazo, Juan de. El tumbo de los Reyes Católicos del concejo de Sevilla. Sevilla: Editorial Católica Espańola, 1968, vol. 4, pp. 122-125.

41 AGS, RGS, 1489-03, 426. Asenjo González, María. Segovia: la ciudad y su tierra a fines del medievo. Segovia: Diputación de Segovia, 1986, p. 210.

42 AGS, RGS 1490-07, 98. Libro de las bulas, fols. 159v-160v. Nueva Recopilación, III, XIX, I. Novísima Recopilación, VII, XIV, I; Gomariz Marín, Antonio. Documentos de los Reyes Católicos (14921504). Murcia: Real Academia Alfonso X El Sabio, 2000, pp. 686-688. En 1498 los regidores de Córdoba nombraron procuradores para jurar a la heredera, la infanta Isabel, a los que se entregó un memorial para los Reyes Católicos que, entre otras cosas, contenía propuestas sobre las alcabalas de los herradores y los exámenes de los albéitares (AMC, AC 1498; 4-IV-1498).
} 
JOSÉ DAMIÁN GONZÁLEZ ARCE

LOS MUNICIPIOS CONTRA EL CENTRALISMO MONÁRQUICO. LA OPOSICIÓN CONCEJIL

A LOS ALCALDES MAYORES DE LAS PROFESIONES SANITARIAS EN LA CASTILLA DEL SIGLO XV

municipales. En 1492, tras el paso de los examinadores mayores, el ayuntamiento manifestó que había muchos herradores que no sabían herrar y ordenó que los ejecutores y Rodrigo Herrador, alcalde gremial de los herreros, los evaluasen. Era costumbre que los herreros examinasen a los albéitares, y estos a los otros. En 1499 mandó que los herreros pasasen otro examen, para detectar a los incapaces; mientras que en 1500 algunos protestaron porque les exigían cartas de examen, que no debían presentar, pues no eran herradores albéitares. Sobre este particular hubo discrepancias entre los regidores, pues según unos debían ser evaluados por los alcaldes mayores, como los herradores, mientras que para otros no les afectaba la pragmática de ese año y su labor había sido dada por buena implícitamente cuando estuvo la corte en la ciudad. Fue esta la postura que prevaleció, así que al ańo siguiente, 1501, los protoalbéitares solicitaron de los monarcas que los corregidores de Murcia, Ronda y Antequera comprobasen si en estas localidades se ejercía sin estar examinado ${ }^{43}$.

Con Juana I no cambió este estado de cosas. En 1508 instituyó a Sebastián de Zamora, de esa localidad, y a Ambrosio, herrador vallisoletano, como alcaldes examinadores vitalicios, con las atribuciones del nombramiento de 1500 . En 1516 era sacada copia de la citada designación ${ }^{44}$. Y, como en tiempos de sus padres, continuaba la corrupción en estas canonjías. En 1529 el concejo de Burgos protestaba ante Carlos I porque los alcaldes mayores daban licencias en blanco sin realizar examen alguno a los aspirantes a albéitar ${ }^{45}$.

\section{Conclusión}

La implantación por la monarquía de delegados que fiscalizasen centralizadamente las actividades sanitarias, y que condujesen a la creación de órganos colegiados con competencias legislativas, judiciales y policiales, siguió a lo largo del siglo xv un tortuoso camino lleno de contratiempos, que no permitieron alcanzar plenamente los objetivos pretendidos hasta la siguiente centuria.

Primero, porque los concejos se resistieron a perder las competencias exclusivas que hasta entonces tuvieron para evaluar la capacidad de los profesionales, supervisarlos y autorizar su trabajo; y solo de manera progresiva los monarcas consiguieron que las entregasen a sus alcaldes mayores. Proceso que distaba de haberse completado a comienzos del siglo XVI.

Segundo, porque los propios alcaldes mayores hicieron poco por ser aceptados por las ciudades, donde eran vistos como voraces exactores, más dispuestos a atender a su interés personal que al general, para lo que delegaban, generalmente a cambio de dinero, en lugartenientes locales, igual de rapaces y prestos al cohecho y prevaricación,

43 AMM, AC 1480-81, fols. 30r-31r. AGS, RGS, 1501-08, s. f. GonZÁlez ArCe, Los gremios medievales, pp. 136, 141-142, 168.

44 Gomariz Marín, Antonio. Documentos de Juana I (1505-1510). Murcia: Real Academia Alfonso X El Sabio, 2006, pp. 322-326.

45 AMB, HI 3296. 
JOSÉ DAMIÁN GONZÁLEZ ARCE
238 LOS MUNICIPIOS CONTRA EL CENTRALISMO MONÁRQUICO. LA OPOSICIÓN CONCEJIL
A LOS ALCALDES MAYORES DE LAS PROFESIONES SANITARIAS EN LA CASTILLA DEL SIGLO XV

que a menudo se dejaban sobornar por los aspirantes a ejercer dichas profesiones. Esta corrupción aumentó la resistencia municipal a los representantes reales y llevó a la Corona a prohibir las lugartenencias.

Y, tercero, en el ánimo de los monarcas estuvo que sus alcaldes mayores tuviesen, como su nombre indica, potestad judicial, para entender en exclusiva en sus respectivos oficios. Sin embargo, la antedicha corrupción, con lo que conllevaba de desprestigio, así como las disensiones entre ellos, muchas veces derivadas del afán de lucro que les llevaba a colisionar en el nombramiento de delegados y en el ejercicio de sus atribuciones, frustraron en la práctica la pretensión de los Reyes Católicos de que sus protomédicos y protoalbéitares formasen un tribunal colegiado con el que uniformar la doctrina médica, jurídica y normativa. 